\title{
19 Feedback from French nursing staff in gerontology
}

\author{
Health reorganisation \\ acceptance related to \\ COVID-19 crisis
}

\section{Pauline Gouttefarde, Chloé Gaulier, Sébastien \\ Rabier, Vincent Augusto, Caroline Dupré, Solène \\ Dorier, Jessica Guyot and Nathalie Barth}

Faced with the global COVID-19 pandemic, marked by urgency and uncertainty, the French healthcare system had to undergo a completely reorganisation so as to provide a response adapted to the health demands of the region surveyed (Auvergne-Rhône-Alpes, France). In order to protect and foster the health and the quality of work life for caregivers in the region, it is important to be able to anticipate future exceptional health situations. To do this, we need to understand the factors that have influenced the acceptance (or not) by caregivers, of the changes implemented during the first months of the Covid epidemic. The 'ARECOVID' project is a sociological study of the opinions, representations and experiences of caregivers. Through a qualitative and quantitative approach, we have sought to gain an indepth understanding of the subjective reality of caregivers with regard to the extent, nature and complexity of the organisational changes in the healthcare system. A total of 472 participants from all medical sectors (medical and paramedical, hospital and non-hospital, medical and social institutions) were surveyed, with the aim of studying the acceptance (or not) by caregivers, of changes relating to crisis management and of identifying potential levers for improvement, and any related obstacles.

\section{Introduction}

Although several studies have highlighted the major reorganisation of care and the lack of human and material resources faced by care professionals, few have studied the consequences and experiences of caregivers. This study also attempts to shed light on the obstacles and levers to the acceptance of 
organisational changes due to the health crisis by caregivers working with the older persons.

The international alert concerning COVID-19 obliged the French Government, through the directives of the Ministry of Solidarity and Health, to mobilise and restructure the French healthcare system so that it could prepare and cope with the imminent spread of the virus. In France, this mobilisation focused on the detection and management of possible and confirmed cases. Care was mainly provided in Covid-certified establishments and mostly concerned hospitals. Nevertheless, non-hospital facilities (i.e, local doctor's clinic) and the social and medico-social sector have also had a key role in managing the Covid crisis, playing a role in detecting new cases, in isolating suspected or detected cases and in managing and mitigating the spread of the pandemic (Ministère des Solidarités et de la Santé 2020; Organisation Mondiale de la Santé 2020).

The escalation to Level 3 on 14 March 2020, forced the government to make greater demands on healthcare sector participants. In order for the ORSAN REB plan (Organisation of the Health System Response in Exceptional Health Situations for Epidemic and Biological Risks) to be effective, all healthcare sector participants had to be mobilised and coordinated. These unprecedented changes led to major organisational changes in healthcare practices.

Typically, three types of organisational change are identified and defined according to several criteria related to the Extent, Pace and Breadth (or Depth) of these changes (Giroux 1991; Guilhorn \& Trepo 2001). With COVID, we are faced with a so-called 'radical' change, since major by its nature and corresponding to a genuine crisis (Soparnot 2004: 31). Radical change is recommended where there be an unstable context. Radical change profoundly disrupts the usual way of doing things (Guilhon 1998: 98-107; Soparnot 2004: 31-42; Vas \& Ingham 2004: 25-32).

And indeed, the COVID-19 epidemic has led to a major reorganisation of care in France. Since the older persons are potentially the most at risk from the virus, because of the serious forms associated with it $(16.6 \%$ of positive cases are between 70 and 79 years old and $18.4 \%$ are 80 years old or older (Verity et al. 2020)), caregivers in facilities caring for the older persons have undergone disproportionately more changes in their work. It is likely that these changes led to difficulties and required significant adaptation efforts by these staff, affecting their perception of the measures taken as well as their acceptance thereof. In fact, several questions can arise: How did caregivers in facilities caring for the older persons perceive and experience the reorganisation of the healthcare system? Did they accept this reorganisation? Did acceptance of the changes differ according to the work contract status of the caregivers? By 'status', we mean that the caregivers either have a full-time employer (i.e., they are 'institutional caregivers' or 'paramedical caregivers') or they are self-employed. What factors were identified as facilitating or hindering acceptance of these changes? 
Several models attempt to capture the modalities inherent in the acceptability (and ultimately acceptance) of using a new tool or embracing a new organisation. For example, the Technology Acceptance Model (TAM) deals with behavioural intention, a factor that leads people to use a technology (Davis 1985). But another model offers a better explanatory capacity for behavioural intention: the 'Unified Theory of Acceptance and Use of Technology' (UTAUT) (Venkatesh et al. 2003:425). This model proposes 4 main factors influencing the behavioural intention and use of a new feature (tool, organisation, system, etc.): performance expectancy; effort expectancy (i.e., the degree of ease associated with use); facilitating conditions, and lastly, social influence (i.e., the influence of the people around the individual and their perception of the new feature) (Bobillier-Chaumon \& Dubois 2009: 355-382; Lewin 1946: 34-46; Venkatesh et al. 2003:425).

Although UTAUT already offered a comprehensive framework for satisfactory acceptance, an extension of this model was subsequently developed. Venkatesh et al. thus added three new constructs to create UTAUT-2 (Venkatesh et al. 2012:157-178). Hedonic Motivation, referring to the satisfaction or pleasure derived from using a new technology; Price Value, referring to the cost of implementing the new feature; and lastly Habit, referring to the extent to which individuals tend to adopt automatic behaviours as a result of learning (Limavem et al. 2007:705). This extension of the original UTAUT model improved the explanation of the variance in behavioural intention, to wit: whereas the first version of UTAUT explained $56 \%$ of behavioural intention, UTAUT-2 allowed for $74 \%$ of behavioural intention to be taken into account (Venkatesh et al. 2012:157-178).

In an attempt to answer the questions set out above, an analysis of the acceptance of these changes, with respect to the UTAUT-2 model, was conducted among caregivers working with the older persons. In the long term, the aim is to better anticipate the impact of the changes within healthcare structures, particularly with a view to future epidemic waves.

The aim of this research was to understand how the reorganisation of healthcare has been experienced by caregivers working with the older persons. From a comprehensive and interventional point of view, the aim was to identify factors identified as facilitating or hindering acceptance of these changes.

\section{Method}

The study used a mixed methodology, combining qualitative (survey by semi-structured interviews) and quantitative (survey by questionnaire) approaches. The aim of the questionnaires was to gauge, over a large sample, the degree of acceptance of the changes resulting from the reorganisation of health services. The aim of the interviews was to analyse and understand the perceptions and experiences of the healthcare professionals surveyed (Corbière \& Larivière 2014; Flick 2020:135-141). 


\section{Survey by semi-structured interviews}

The aim here was to understand the subjective reality experienced by caregivers in the face of the management of the COVID-19 health crisis (understanding and operationalisation of the changes as well as the feelings and experiences associated with it). Our sample was made up of ten caregivers (five men and five women; average age 31.1 years), mainly doctors (seven doctors, one intensive care anaesthetist, one senior nurse, one rheumatology intern), all practising in France in the Auvergne-Rhône-Alpes region (AURA).

All the semi-structured interviews were done by the same interviewer, using a semi-structured interview guide. To start, some socio-demographic data pertaining to the interviewees were collected. Then came the interview guide, structured around four themes: their perception of the changes imposed by the crisis; how the caregivers personally experienced these changes; the acceptability of these changes; and lastly, perspectives ensuing from the reorganisation. The interviews were conducted during the month of May 2020, i.e., just after the first pandemic wave in France. ${ }^{1}$ The analysis of the interviews was carried out using NVivo version 11 software. A horizontal thematic analysis was carried out in order to identify recurring themes (Bardin 2013).

\section{The questionnaire survey}

This survey was conducted among a population encompassing all caregivers practising their profession in the AURA region and caring for older persons patients. More specifically, the survey population was composed of three groups of participants: institutional caregivers (hospitals/medical-social establishments), paramedical caregivers (hospitals/medical-social establishments) and self-employed or home-based caregivers. A sample of 472 voluntary caregivers was recruited using a non-random, voluntary sampling method. Of these, $83.9 \%$ were women and $15.47 \%$ men; average age of 44.38 years (youngest was 18, and eldest was 68). Most of the survey participants were nurses. A large majority of the survey participants came from the field of non-hospitalised medicine, with $51.48 \%$ of professionals working in a private practice, $13.98 \%$ at home, $14.83 \%$ practising their profession in a nursing home and $12.92 \%$ in a hospital.

This questionnaire was developed using LimeSurvey software. It consisted of three main sections: (i) the experience and extent of organisational changes, (ii) the presence and use of psychological support units to the intention of caregivers, and (iii), the acceptance, by caregivers, of how the Covid crisis was managed. This last part has been developed on the basis of behavioural factors identified by the second version of the Unified Theory of Acceptance and Use of Technology (UTAUT-2) (Venkatesh et al. 2012) which has a total of seven factors influencing the behavioural intention to 
use a new feature: performance expectancy (usefulness), effort expectancy (ease of use), facilitating conditions, social influence (influence of relatives and their perception of the tool), hedonic motivation, price value and habit. These different factors were made part of the questionnaire in order to highlight the factors of acceptance or resistance to changes in the practices of caregivers working with older persons people.

The questionnaire was distributed online (by e-mail and social networks) in order to respect the anonymity of the respondents and the confidentiality of the responses for the months of May and June 2020. The results were statistically analysed in two steps: the calculation of position data for the descriptive questions (minimum and maximum responses, percentages or averages) and the analysis of the consistency of scales with calculation of Cronbach's alphas (Cescup 2014).

\section{Results}

\section{A radical reorganisation of healthcare}

\section{Changes in the pace of work}

Recurrently, the participants in this study report that they have witnessed a complete change in the organisation within health establishments (hospitals as well as nursing homes). According to the data collected, these changes appear to be more significant for institutional caregivers (including hospitals) than for self-employed caregivers $(88.2 \%$ versus $51.69 \%)$. Most questionnaire survey participants reported an increase in their workload: $59.21 \%$ of caregivers employed by medical establishments, and $50 \%$ of self-employed caregivers reported having worked more hours than usual: "What also plagued me was managing all the extra work, of which we already had a lot" (senior nurse, Geriatric hospital).

\section{A reorganisation in the sector that facilitated the emergence of new} skills

Caregivers who could no longer perform their usual duties were assigned to these dedicated units. It would appear that some structures/services were much more affected than others. The results show that $79.54 \%$ of the participants say that they had to acquire new work habits quickly (hygiene measures, administration of treatment procedures, etc.). Many outpatient and non-emergency consultation services were suspended, and the premises were fitted out to receive patients with COVID-19. As a result, hospital doctors report many late consultations and more serious pathologies, wounds and problems than usual: "I think above all that they were afraid to come; you have many people who, although with fractures or in a cast, did not want to come" (Sports doctor, Emergencies Unit). 
A lack of personal protective equipment generating a fear of risk, particularly for self-employed caregivers

With regard to the perception of risk, the main change mentioned by the respondents was PPE Management. A full $44 \%$ of respondents considered that they lacked protective personal equipment (PPE) such as masks, gloves and similar. This insufficiency in terms of PPE, noted in all health sectors (hospitals, medico-social establishments, local doctors clinics), seemed, based on the quantitative data collected, even more problematic for self-employed caregivers. Indeed, $43.93 \%$ of self-employed caregivers reported this issue (compared with $29.63 \%$ of institutional caregivers and $22.06 \%$ of paramedical caregivers). Caregivers spoke at length about their difficulties in obtaining PPE and several comments reveal a feeling of insecurity and anxiety regarding these missing resources.

I was very concerned that we would lack PPE. That was sometimes a bit complicated because we really felt we were in a tight spot.

(Doctor, geriatric hospital)

This variable can be linked to the fear of risk and contamination; indeed, $70.84 \%$ of the caregivers expressed a fear of contaminating their family and $68.03 \%$ their patients. The analysis reveals that self-employed caregivers were the most concerned about transmitting the virus. The population sample declaring that they had the greatest difficulty in obtaining the necessary PPE is therefore also the population that expressed the strongest feeling of risk of contamination. Our acceptance scales bear witness to this situation since the "risk perception" variable is very noticeable for self-employed caregivers. This variable would therefore not facilitate acceptance in the management of a health crisis.

\section{End-of-life management: the use of digital tools as an alternative}

Digital tools have played an important role in this context of health crisis. They were mainly used by paramedical caregivers in order to communicate with the families of patients (as reported by $70.55 \%$ of caregivers) and to enable patients to call their families (as reported by $80.89 \%$ of caregivers). Institutional caregivers and self-employed caregivers mainly used digital tools in order to communicate with other healthcare professionals $(74.07 \%$ and $56.76 \%$ respectively). On the whole, the telephone was the most used communications tool ( $80.88 \%$ of caregivers), followed by videoconferencing $(51.85 \%)$ and telemedicine $(29.63 \%)$. Paramedical caregivers considered these communications tools as playing an essential role in maintaining a relationship (healthcare professional <=> family <=> patient). However, although these technologies are perceived as necessary, difficulties persist, particularly with regard to using these technologies and the presence or absence of 
functional equipment. Virtual communications does not compensate for the lack of direct contact among older persons.

They come from a generation that is clearly not at home with our new technologies and for some, seeing their loved ones on a screen was complicated to understand. For some it worked very well, but for most it was not completely satisfactory and it didn't completely make up for the lack of visits, although it's better than nothing.

(Geriatrician doctor, Nursing Home)

End-of-life management is a criterion that particularly impacts healthcare professionals, who reported that they did not always feel they are acting ethically or doing quality work. In our interviews, this feeling of powerlessness with regard to death is expressed.

Sometimes the husband and the wife were in the same service and so we had the wife transferred so that she could hold the husband's hand as he was dying. We tried to be as humane as possible but this was not always the case.

(Anaesthesiologist - Resuscitator, COVID resuscitation)

The issue of end-of-life management and support was raised by the survey participants. However, ancillary and creative solutions enabled families to maintain the connection to COVID-19 residents and patients up to their death. For example, caregivers mentioned the use of digital tools or rituals to make the departure of a patient more humane. Caregivers organised telephone slots dedicated to contacts with families which, they reported, were very beneficial. Although digital tools (videoconferencing, telemedicine, telephone calls) were widely used, they could not be set up everywhere and for all users, particularly the older persons who either didn't know how to use them or did not have the necessary equipment.

We had patients who were very ill and it was difficult to use a digital tool with them.

(MCU-PH, Infectious Diseases Department)

\section{Isolation harmful to patients}

Our survey underlines the negative psychosocial repercussions, on patient health, and in particular on older people, of the organisational changes enacted in response to Covid-19. These new conditions have led to changes in the work of caregivers. Their work evolved into a more supportive and accompanying role with older people. According to replies, the isolation of older persons inside nursing homes, combined with the discontinuance of all social bonds has had a significant negative impact on their mental health. 
It is becoming increasingly difficult for the residents to be cut off from the world (...) it's a kind of tsunami, anxiety, tendency to depression (...), the residents withdraw into themselves, they are much less communicative (...) even with nursing home staff, you can really see that they withdraw into themselves. (...). They feel sad, they have a feeling that they are locked up, in prison, and they miss their family.

(Geriatrician, Nursing Home)

Moreover, visits to older persons persons in nursing home took place under conditions that emphasised protection (plexiglass, social distancing, masks...) and the residents seem to experience difficulties with this.

We can see that there are residents who are almost more disturbed after the visits than before.

(Geriatrician, Nursing Home)

\section{How satisfied were the caregivers with these changes?}

Caregivers are globally satisfied with the new organisation

Overall, caregivers expressed satisfaction with the management of the first pandemic wave. The results of the questionnaire survey show that $88.23 \%$ of institutional caregivers, $75 \%$ of paramedical caregivers and $51.69 \%$ of self-employed caregivers considered that the response reorganisation deployed to deal with the pandemic were on a par with the scale of the emergency.

This overall satisfaction also seems to favour the acceptance of caregivers in the face of this reorganisation. In fact, most of the caregivers interviewed were satisfied with the organisation that had been deployed and found it useful. Furthermore, all the systems put in place in times of crisis seem to have been approved, such as the questionnaires for analysing the state of health of pre-consultation or follow-up of positive patients at Covid-19 at home.

I think it was very well organised and above all with great solidarity.

(MCU-PH, Infectious Diseases Department)

\section{...with nevertheless some reservations}

For $50.05 \%$ of institutional caregivers, the health reorganisation measured deployed to deal with the pandemic did not allow for continuity of care for non-COVID older persons people. Conversely, $66.18 \%$ of paramedical caregivers and $47.3 \%$ of self-employed caregivers responded that this reorganisation sufficiently allowed for continuity of care for non-COVID older persons people. It should be noted that a significant number of self-employed caregivers did not take a position on this issue. Nevertheless, institutional 
caregivers have less trust in government recommendations than do self-employed caregivers. Overall, $24.55 \%$ of survey participants do not trust these recommendations, due to repeated changes in Covid-response measures handed down by the government:

The test procedure that changed every day... and that was a big problem, a source of much anxiety for the teams... one day you were being told to dress the older persons persons and the next day, you were told not to dress them, to help them wash, and not help them wash.

(Doctor, geriatric hospital)

\section{A feeling of support that promotes acceptance}

The caregivers reported feeling valued, both by their colleagues and their loved ones. Overall, $67 \%$ of survey participants felt supported by their family and friends as regards following Covid-response recommendations: $34.27 \%$ of family/friends encouraged survey participants in their work with COVID patients, compared with $28.9 \%$ who did not. More than $66 \%$ of the caregivers felt useful during this pandemic.

Cooperation, Solidarity and Communication between caregivers were the most important aspects highlighted. This cooperation was omnipresent in the decision-making process concerning the care and reorientation of COVID patients, with multidisciplinary choices and decision-making.

We always made decisions as a team to try to find the best solution. There has been a lot of discussion about what kind of care to take.

(Doctor, COVID acute care \& rehabilitation)

\section{Discussion}

Through this study of the acceptance, by caregivers, of organisational changes rolled out in response to COVID-19, we were able to explore how caregivers in the AURA region experienced these changes, as well as their perception thereof. Feedback, opinions and assertions made by the caregivers surveyed allowed us to understand in depth how the healthcare measures implemented in the AURA region were perceived, experienced and accepted by these front-line professionals. The UTAUT-2 model enabled us to identify the factors that influenced the acceptance of caregivers with regards to the new measures and organisation put in place in response to Covid. In the face of an unprecedented epidemic, with no possibility of comparison or reproduction based on past experience, a change in working habits is at the heart of the recommendations for managing this crisis. Therefore, for an effective change in practice, the acceptance, by caregivers, of organisational changes and new rules, can be considered a necessary condition for the effectiveness of public health policies. 


\section{Factors hindering acceptance: what parallel with UTAUT-2?}

\section{The adverse consequences of this crisis on the health of caregivers}

The analysis of our data shows that, above and beyond those changes made in response to Covid, caregivers were exposed to an array of difficulties (PPE, care of non-COVID older persons patients, end-of-life management, patient orientation, pressure from families, etc.). The large workload and the massive influx of patients combined with constantly changing organisational instructions put a heavy strain on the cognitive and adaptive capacities of the caregivers. These decisions, necessarily rapid, repeated and difficult, led to strong psychological tensions and possible cognitive exhaustion (El-Hagea et al. 2020:4). These results converge with those of other studies which reveal that $57 \%$ of institutional caregivers (hospitals/nursing homes/medico-social) claim to have experienced an increase in workload (Fabergas 2020).

On a similar note, several survey doctors reported that they had had disturbed sleep or had taken treatments for anxiety. Similarly, $49.37 \%$ of the caregivers interviewed felt sad (from Sometimes to Frequently). Similar results have been highlighted by the MACSF (mutual insurance company, provider of insurance services for health professionals) found that over $50 \%$ of the surveyed caregivers reported that they continued to experience physical fatigue, anxiety, stress and sleep disorders (MACSF, June 2020).

End-of-life management has been particularly difficult for caregivers. While geriatric caregivers are particularly accustomed to death, restrictions on family visits and limited contact care created a sense of powerlessness in their ranks (Peyrat-Apicella \& Gautier 2020:160-167). It would seem that these negative feelings were not so much caused by death per se, but rather but the suddenness of the onset of death and the support measures (considered inadequate) provided to the dying person (Lefèvre 2020:1). Although the survey caregivers accepted these conditions, in particular in the light of the collective interest, these conditions and this feeling of not staying by the dying person lead to "an internal revolt that is not without consequences for the caregivers and, in particular, hinders their mourning process" (for the deceased older persons person) (Peyrat-Apicella \& Gautier 2020:4).

The repercussions, on the mental health of caregivers, of health emergencies seems to a topic at the heart of current research (Dit 2020; ElHagea 2020; Mutuelle d'assurance du corps de santé français 2020; Peyrat-Apicella \& Gautier 2020; Vignaud \& Prieto 2020). The caregivers surveyed also expressed the wish to have psychological support available onsite, rather than to have a special cell that they have to contact themselves - a remark all the more salient since a large majority of respondent caregivers were not even aware of psychological support services available for caregivers. 
Fear: a brake on acceptance?

The caregivers surveyed commented on the lack of PPE they experienced at the beginning of the crisis. These conditions were a cause for concern amongst caregivers, altering their sense of their professionalism and of their personal safety (El-Hagea et al. 2020:1). 68.03\% of the caregivers surveyed questioned are mainly worried about infecting their relatives or patients. These data coincide with those of other studies, since $14 \%$ of caregivers decided, as a preventive measure, to live apart from their relatives during the pandemic (Mutuelle d'assurance du corps de santé français 2020). This unprecedented health situation forced caregivers to reorganise their personal lives, leading to an upheaval between private and professional life (Vignaud \& Prieto 2020:1). Self-employed caregivers were the least affected by the sweeping changes caused by the Covid. That said, the survey reveals that this was precisely the category that was the least accepting of change. As regards those factors of acceptance of the changes, the Risk Perception variable was very high for self-employed caregivers. Moreover, the survey reveals that this category was the one that most suffered the lack of PPE. A1though self-employed caregivers did not perceive organisational changes to the same extent as other classes of caregivers, those self-employed caregivers who experienced more difficulties replenishing PPE had a strong sense of risk. Self-employed caregivers were also less accepting of the organisational changes deployed in response to Covid. This risk-perception factor, which is part of the UTAUT-2 model, helps to explain the lower acceptance of changes by self-employed caregivers, who did not feel sufficiently protected by the proposed or imposed changes.

\section{Factors facilitating acceptance: the use of UTAUT-2 as an explanatory model}

\section{New work habits that make work easier}

Our study reveals that the caregivers acquired skills and new work habits rapidly (hygiene measures, administration of treatment procedures, etc.) Similarly, according to another study, Covid facilitated the emergence of new working methods for $85 \%$ of caregivers, including $89 \%$ of self-employed caregivers and $81 \%$ of institutional caregivers (Mutuelle d'assurance du corps de santé français 2020). The caregivers responded that they had acquired new skills as a result of having been dispatched to other services where they learned new skills. They spoke of new and rapid work habits. With regard to UTAUT-2 and its Habit factor, individuals tend to adopt automatic behaviours as a result of learning (Limavem et al. 2007). If the behaviour becomes a habit, then users will be more likely to approve of it. This factor is very present here and can promote acceptance of the new organisation. Similarly, these new work habits do not appear to have had a 
significant impact on the sense of efficiency or "performance" as described in UTAUT-2. We can hypothesise that those caregivers who felt overwhelmingly supported, valued and useful have, as a result, been more accepting of organisational change.

\section{Perceived support: a lever for acceptance}

The caregivers surveyed replied that they felt supported and valued, both by their colleagues and their loved ones. The social influence variable in UTAUT-2, which takes into account the influence of the entourage orbiting the individual, indicates that the more the user (here the caregiver) feels that those around him or her are favourable to the adoption of the change (in this case, the new organisation), the more the latter will be inclined to approve of it (Bobillier-Chaumon \& Dubois 2009; Lewin 1946; Venkatesh et al. 2003). We note that the changes rolled out in response to Covid were supported and approved by family and friends, which would encourage acceptance by caregivers. The views of family and friends and society therefore seem to have an impact on the work of professionals and the acceptance (or not) of the changes. Although some cases of violence against caregivers were reported in the media, society at large was supportive of caregivers (clapping each evening at 8 p.m.).

\section{Paradoxically, many changes were well accepted}

Caregivers had to come to terms with a total reorganisation of their work habits. However, the greater the changes (scale, pace, depth, usability, etc.), the more difficult it was for individuals to adhere to them (Bareil 2004; Davis 1985; Hannan \& Freeman 1984; Lewin 1946; Nielsen 1993; Venkatesh et al. 2003). However, caregivers appear to have generally accepted and followed the recommendations. We may wonder about the particularities of this exceptional situation, which has led to many changes that have, in the end, been favourably accepted by caregivers caring for the older persons.

The caregivers have shown a voluntary and determined commitment without which the reorganisation would not have been possible (El-Hagea et al. 2020:1). We can assume that the key role played by the medical professions during Covid had an important impact on the acceptance of health recommendations. Caregivers wanted to feel useful and in their rightful place when the pandemic hit. The favourable acceptance of organisational changes by the caregivers seems to have been impacted by the Performance Expectancy factor. Indeed, change appeared to be unavoidable in order to cope with the COVID-19 crisis. Moreover, most survey respondents replied that they felt more valued by others during the crisis.

However, M-J Del Volgo notes that it is "dangerous to consider caregivers as heroes." To be a hero means to sacrifice yourself, to suffer in silence. The hero does not ask for help nor special resources. The hero is a superman. 
To consider caregivers as heroes is to place immense responsibility upon their shoulders all the while preventing them from recognising "their own vulnerability" (Peyrat-Apicella \& Gautier 2020:1). This societal pressure on caregivers raises questions about the nature of acceptance of change (by caregivers). Indeed, we may wonder whether this acceptance is not strongly induced by social pressure. We can assume that the acceptance of changes rolled out in response to Covid -19 could be a forced acceptance, imposed by forces of an ethical nature, and by the inherent social desirability of the way in which society see the medical professions. According to this reasoning, caregivers are tempted to accept Covid-induced changes so as to adopt the behaviours expected by society (Festinger 1957).

\section{For further discussion...}

The progress and persistence of this health crisis over several months has highlighted the need for a comprehensive approach in order to learn lessons from the first wave of this epidemic. Our research shows that the crisis has had an emotional impact on caregivers (stressful situations, working conditions, death of patients, suffering of residents' families...), and the French Academy of Medicine recommends that particular attention be paid, over a long period of time, to the mental health of the caregivers involved in the COVID-19 crisis. One of the keys to future health crises would be make psychological and social support available for caregivers. This research allows us to start thinking about anticipating future health crises. Indeed, by highlighting the brakes and levers for the acceptance of organisational changes due to a health crisis by the caregivers, it may be possible to optimise the hospital organisation for the future. New technologies are increasingly being used to optimise hospital organisation. For example, real time localisation systems allow to locate patients and professionals in real time in hospitals. Some studies demonstrate the relative acceptance of these new technologies by users (Bowen et al. 2013; Fisher \& Monahan 2012; Kamel Boulos \& Berry 2012). But what about an older audience? Indeed, after the age of 70 , the use of new technologies becomes more rare: for example, $86 \%$ of people over 70 do not have a computer (Besson 2012; Bigot \& Croutte 2007). For several years now, we have been witnessing the phenomenon of the "digital divide," which has slowed down the benefits of new technologies for the care of the older adults.

\section{Notes}

1 Santé Publique France, Agence régionale de santé (ARS) Auvergne-RhôneAlpes, Réseau Sentinelles, SOS Médecins de France, Société Française de Médecine d'Urgence (SFMU), Fédération Française des Observatoires Régionnaux des Urgences (FEDORU), Société Française d'Anesthésie et de Réanimation (SFAR), Société de Réanimation de Langue Française (SRLF), Institut national de la statistique et des études économiques (INSEE), Institut national de 
la santé et de la recherche médicale (INSERM), Institut Pasteur, \& CNR des virus des infections respiratoires. (2020). Point épidémio régional AuvergneRhône-Alpes, Spécial COVID-19. https://www.santepubliquefrance.fr/content/ download/244231/2568258

\section{References}

Bardin, L. (2013). L'analyse de contenu. Paris cedex 14, France: Presses Universitaires de France. https://doi.org/10.3917/puf.bard.2013.01

Bareil, C. (2004). Gérer le volet humain du changement (Transcontinental).

Besson, E. (2012). France numerique2012. Plan de développement de l'économie numérique, 2008. http://francenumerique2012.fr)

Bigot, R., \& Croutte P. (2007, décembre). La diffusion des technologies de l'information dans la société française Rapport du CREDOC. http://www.arcep.fr/ uploads/tx_gspublication/etude-credoc-2007.pdf

Bobillier-Chaumon, M.-É., \& Dubois, M. (2009). L'adoption des technologies en situation professionnelle: Quelles articulations possibles entre acceptabilité et acceptation? Le travail humain, 72(4), 355382. https://www.cairn.info/revue-letravail-humain-2009-4-page-355.htm

Bowen, M.E., Wingrave, C.A., Klanchar, A., \& Craighead, J. (2013). Tracking technology: Lessons learned in two health care sites. Technology and Health Care, 21(3), 191-197.

Cescup. (2014). L'alpha de Cronbach. https://cescup.ulb.be/lalpha-de-cronbach/

Corbière, M., \& Larivière, N. (2014). Méthodes qualitatives, quantitatives et mixtes dans la recherche en sciences humaines, sociales et de la santé. Presses de l'Université du Québec, 720p.

Davis, F. (1985). A technology acceptance model for empirically testing new end-user information systems: Theory and results. https://scholar.harvard.edu/bmiddlet/ publications/technology-acceptance-model-empirically-testing-new-end-userinformation

Dit, B. (2020, mai 22). Vécu psychologique de l'épidémie COVID-19. ISNI. https:// isni.fr/vecu-psychologique-de-lepidemie-covid/

El-Hagea, W., Hingrayc, C., Lemogned, C., Yrondif, A., Brunaulta, P., Bienvenuh, T., Etaini, B., Paqueti, C., Gohiel, B., Bennabim, D., Birmesn, P., \& Sauvageto, A. (2020). Les professionnels de santé face à la pandémie de la maladie à coronavirus (COVID-19). Elsevier Connect. https://www.elsevier.com/fr-fr/connect/psy/ les-professionnels-de-sante-face-a-la-pandemie-de-la-maladie-a-coronaviruscovid-19

Fabregas, B. (2020, juin 3). Les soignants interrogés sur leur vécu de la crise sanitaire. Infirmiers.com. https://www.infirmiers.com/actualites/actualites/covid-19-etimpacts-sur-professionnels-de-sante.html

Festinger, L. (1957). A theory of cognitive dissonance. Row, Peterson.

Fisher, J.A., \& Monahan, T. (2012). Evaluation of real-time location systems in their hospital contexts. International Journal of Medical Informatics, 81(10), $705-712$.

Flick, U. (2020). Hearing and being heard, seeing and being seen: Qualitative inquiry in the public sphere. Introduction to the Special Issue. Qualitative Inquiry, 26(2), 135-141. https://doi.org/10.1177/1077800419857766

Giroux, N. (1991). La gestion du changement stratégique. Gestion, 16(2), 8-14. 
Guilhon, A. (1998). Le changement organisationnel est un apprentissage. Revue française de gestion, 120, 98-107.

Guilhon, A., \& Trepo, G. (2001). Réussir les changements par le développement de l'apprentissage organisationnel les leçons du cas de Shell.". Gérer et Comprendre, septembre, n 65.

Hannan, M.T., \& Freeman, J. (1984). Structural inertia and organizational change. American Sociological Review, 49(2), 149164. https://doi.org/10.2307/2095567

Kamel Boulos, M.N., \& Berry, G. (2012). Real-time locating systems (RTLS) in healthcare: A condensed primer. International Journal of Health Geographics, $11,25$.

Lefèvre, G. (2020, avril 1). Covid-19: Paroles de soignants et d'accompagnants. Portail CFDT.fr. https://www.cfdt.fr/portail/actualites/crise-du-covid-19/ covid-19-paroles-de-soignants-et-d-accompagnants-srv1_1107165

Lewin, K. (1946). Action research and minority problems. Journal of Social Issues, 2(4), 3446. https://doi.org/10.1111/j.1540-4560.1946.tb02295.x

Limayem, M. Hirt, S.G., \& Cheung, C.M.K. (2007). How habit limits the predictive power of intention: The case of information systems continuance. MIS Quarterly, 31(4), 705. https://doi.org/10.2307/25148817

Ministère des Solidarités et de la Santé. (2020). Préparation au risque épidémique Covid-19: Guide méthodologique. https://solidarites-sante.gouv.fr/IMG/pdf/ guide_methodologique_covid-19-2.pdf

Mutuelle d'assurance du corps de santé français. (2020). COVID-19: Quel impact sur les soignants? MACSF.fr. https://www.macsf.fr/actualites/ covid-19-impact-sur-les-soignants

Nielsen, J. (1993). Usability engineering. Morgan Kaufmann.

Organisation Mondiale de la Santé. (2020). La COVID-19 a de graves répercussions sur les services de santé soignant les maladies non transmissibles. https:// www.who.int/fr/news/item/01-06-2020-covid-19-significantly-impacts-health-services-for-noncommunicable-diseases

Peyrat-Apicella, D., \& Gautier, S. (2020). COVID-19: Aux frontières de la folie. Éthique \& Santé, 17(3), 160167. https://doi.org/10.1016/j.etiqe.2020.06.001

Santé Publique France, Agence régionale de santé (ARS) Auvergne-Rhône-Alpes, Réseau Sentinelles, SOS Médecins de France, Société Française de Médecine d'Urgence (SFMU), Fédération Française des Observatoires Régionnaux des Urgences (FEDORU), Société Française d'Anesthésie et de Réanimation (SFAR), Société de Réanimation de Langue Française (SRLF), Institut national de la statistique et des études économiques (INSEE), Institut national de la santé et de la recherche médicale (INSERM), Institut Pasteur, \& CNR des virus des infections respiratoires. (2020). Point épidémio régional Auvergne-Rhône-Alpes, Spécial COVID-19. https://www.santepubliquefrance.fr/content/download/244231/2568258

Soparnot, R. (2004). Lévaluation des modèles de gestion du changement organisationnel: De la capacité de gestion du changement à la gestion des capacités de changement. Gestion, 29(4), 3142. https://www.cairn.info/revue-gestion-20044-page-31.htm

Vas, A., \& Ingham, M. (2004). Réorganisation, optez pour le grand angle. L'expansion Management Review, juin, 2532.

Venkatesh, V., Morris, M.G., Davis, G.B., \& Davis, F.D. (2003). User acceptance of information technology: Toward a unified view. MIS Quarterly, 27(3), 425. https:// doi.org/10.2307/30036540 


\section{Pauline Gouttefarde et al.}

Venkatesh, V., Thong, J.Y.L., \& Xu, X. (2012). Consumer acceptance and use of information technology: Extending the unified theory of acceptance and use of technology. MIS Quarterly, 36(1), 157178. https://doi.org/10.2307/41410412

Verity, R., Okell, L.C., Dorigatti, I., Winskill, P., Whittaker, C., \& Imai, N. (2020). Estimates of the severity of coronavirus disease 2019: A model-based analysis, Lancet Infect Disease, 20, 669-677.

Vignaud, P., \& Prieto, N. (2020). Impact psychique de la pandémie de Covid-19 sur les professionnels soignants. Actualités Pharmaceutiques, 59(599), 5153. https:// doi.org/10.1016/j.actpha.2020.08.013 